\title{
Poliploidização em ápices caulinares de bananeira e seus efeitos morfofisiológicos in vitro
}

\author{
Frederico Henrique da Silva Costa(1), Moacir Pasqual(2), Sebastião de Oliveira e Silva ${ }^{(3)}$, \\ Honorato Pereira da Silva Neto(3), Edson Perito Amorim ${ }^{(3)}$ e Janay Almeida dos Santos-Serejo ${ }^{(3)}$
}

\begin{abstract}
(1)Universidade do Oeste Paulista, Curso de Agronomia, Rodovia Raposo Tavares, Km 572, Limoeiro, CEP 19067-175 Presidente Prudente, SP. E-mail: frederico@unoeste.br (2)Universidade Federal de Lavras, Caixa Postal 3037, CEP 37200-000 Lavras, MG. E-mail: mpasqual@dag.ufla.br (3)Embrapa Mandioca e Fruticultura Tropical, Caixa Postal 007, CEP 44380-000 Cruz das Almas, BA. E-mail: ssilva@cnpmf.embrapa.br, honorato@cnpmf.embrapa.br, edson@cnpmf.embrapa.br, janay@cnpmf.embrapa.br
\end{abstract}

Resumo - O objetivo deste trabalho foi avaliar as respostas morfofisiológicas de ápices caulinares de diploides de Musa acuminata submetidos à poliploidização in vitro. Foram avaliados os antimitóticos colchicina $(0,1,25$, $2,5,3,75$ e $\left.5 \mathrm{mmol} \mathrm{L}^{-1}\right)$ e orizalina $\left(0,15,22,5\right.$ e $\left.30 \mu \mathrm{mol} \mathrm{L}^{-1}\right)$, e dois tempos de poliploidização: 24 e 48 horas para colchicina, e 3 e 7 dias para orizalina. A aplicação de colchicina reduziu significativamente a sobrevivência e o número médio de brotos dos ápices. A orizalina teve um leve efeito negativo na sobrevivência dos ápices caulinares e influenciou positivamente o número médio de brotos por explante. Observou-se alta mortalidade e níveis acentuados de oxidação dos explantes primários tratados e regenerados, com ambos os antimitóticos. No entanto, a capacidade morfogenética dos explantes foi restabelecida após sucessivos subcultivos em meio fresco, e as brotações produzidas foram alongadas/enraizadas e aclimatizadas com sucesso. O uso de colchicina, nas concentrações de 1,25 e $3,75 \mathrm{mmol} \mathrm{L}^{-1}$, e de orizalina representam abordagens viáveis e práticas para programas de melhoramento da bananeira. Os efeitos morfofisiológicos observados in vitro são importantes para definir estratégias de indução de poliploidia em bananeira.

Termos para indexação: Musa acuminata, antimitóticos, biotecnologia, colchicina, morfogênese, orizalina.

\section{Polyploidization in banana shoot apex and its morphophysiological effects in vitro}

\begin{abstract}
The objective of this work was to evaluate the morphophysiological responses of shoot apex of diploid Musa acuminata subjected to in vitro polyploidization. The antimytotic agents colchicine $(0,1.25$, $2.5,3.75$, and $\left.5 \mathrm{mmol} \mathrm{L}^{-1}\right)$ and oryzaline $(0,15,22.5$, and $30 \mu \mathrm{mol} \mathrm{L}-1)$, and two polyploidization periods were evaluated: 24 and 48 hours for colchicine, and 3 and 7 days for oryzaline. The application of colchicine significantly reduced the survival and the average number of shoots. Oryzaline had a slightly negative effect on shoot apex survival and positively influenced the average number of shoots per explant. High mortality and accentuated oxidation of treated and regenerated explants were observed with both antimytotics. However, the morphogenetic capacity of the explants was reestablished after successive sub-cultivations in fresh media, and the produced shoots were elongated/rooted and acclimatized successfully. Colchicine, at 1.25 and $3.75 \mathrm{mmol} \mathrm{L}^{-1}$ concentrations, and oryzaline represent a viable and practical approach for banana breeding programs. The morphophysiological effects observed in vitro are important to define strategies for induction of polyploidy in banana plants.
\end{abstract}

Index terms: Musa acuminata, antimytotic agents, biotechnology, colchicine, morphogenesis, oryzaline.

\section{Introdução}

As variedades de bananeira tipo Cavendish, como a 'Grande Naine' e a 'Nanicão', são as únicas com características adequadas para exportação e representam mais de $45 \%$ da produção mundial de bananas. Contudo, esses genótipos são suscetíveis às principais pragas da bananeira e apresentam estreita base genética, o que requer estudos que viabilizem o melhoramento genético e garantam sua proteção fitossanitária (Silva et al., 2002; Bakry et al., 2009).

O método de melhoramento mais utilizado em bananeira é o convencional, que consiste no cruzamento de diploides pré-melhorados AA com triploides comerciais AAB. Essa metodologia é a mais utilizada pela Embrapa e possibilitou a obtenção de uma série de cultivares tetraploides $\mathrm{AAAB}$ com boas características

Pesq. agropec. bras., Brasília, v.46, n.8, p.805-813, ago. 2011 
de fruto e de resistência a pragas (Silva et al., 2001, 2002). Entretanto, esse método é ineficiente para a criação de cultivares triploides AAA do subgrupo Cavendish, em virtude da esterilidade observada nesses genótipos.

Uma das alternativas para contornar a esterilidade em bananeira é o uso da poliploidização in vitro. Essa técnica possibilita gerar novos híbridos triploides secundários AAA resistentes a pragas e com boas características agronômicas, mediante a produção in vitro de plantas autotetraploides AAAA férteis, que após avaliadas e selecionadas no campo, são utilizadas como genitor em cruzamentos com diploides melhorados AA (Van Duren et al., 1996; Silva et al., 2001; Ganga \& Chezhiyan, 2002; Bakry et al., 2007).

A principal forma de induzir autotetraploides em bananeira consiste na aplicação de antimitóticos, como a colchicina, em ápices caulinares, sob condições in vitro, seguida de sucessivos subcultivos para regeneração das plantas, pré-seleção e identificação dos tetraploides estáveis. Apesar de seu amplo uso, a colchicina $\left(\mathrm{C}_{22} \mathrm{H}_{25} \mathrm{NO}_{6}\right)$ apresenta alta toxicidade ao ser humano, elevada fitotoxicidade in vitro e, quando utilizada em altas concentrações, pode aumentar a frequência de mixoploidia nas plantas regeneradas (Van Duren et al., 1996; Ganga \& Chezhiyan, 2002). Por essas razões, outros compostos, como a orizalina, têm sido estudados em protocolos de duplicação de cromossomos por apresentar baixa fitotoxidez in vitro e maior afinidade com a proteína do fuso mitótico (tubulina), o que resulta em alta atividade de poliploidização. Além disso, a orizalina é utilizada em concentrações mil vezes menores e apresenta eficiência similar ou mesmo superior à da colchicina (Khosravi et al., 2008).

Os principais fatores que determinam o sucesso da poliploidização in vitro são o tipo, a concentração e o período de exposição do agente antimitótico, bem como o tipo de explante e de genótipo utilizado (Asif et al., 2000; Ganga \& Chezhiyan, 2002; Bakry et al., 2007). Portanto, uma etapa indispensável na poliploidização induzida consiste em determinar a sensibilidade dos explantes ao tipo, à concentração e ao período de aplicação do antimitótico, ao avaliar as respostas morfogenéticas e fisiológicas in vitro dos explantes tratados e das plantas regeneradas.
As pesquisas sobre indução de poliploidização em bananeira são incipientes, sobretudo no Brasil, o quarto maior produtor mundial de bananas e detentor de um dos principais programas de melhoramento genético de bananeira do mundo. Além disso, a maioria dos estudos sobre indução de poliploides utiliza altas concentrações de antimitóticos e carece de informações sobre os efeitos in vitro da poliploidização. Nesse sentido, o presente trabalho é inovador, pois utiliza concentrações mais baixas para reduzir a fitotoxicidade exercida pela colchicina, sem prejudicar a capacidade de indução de autotetraploides.

O objetivo deste trabalho foi avaliar as respostas morfofisiológicas de ápices caulinares de diploides de Musa acuminata submetidos à poliploidização in vitro.

\section{Material e Métodos}

O material vegetal consistiu dos genótipos diploides de bananeira (AA) Tong Dok Mak (TDM), NBA-14 e Malbut, obtidos do Banco Ativo de Germoplasma de Banana da Embrapa Mandioca e Fruticultura Tropical, e selecionados por apresentarem boa qualidade de fruto.

Para obtenção dos explantes, foi utilizado protocolo específico, desenvolvido para o presente trabalho. Nesse protocolo, ápices caulinares foram inicialmente estabelecidos in vitro, em meio de cultura MS, com vitaminas e macro e micronutrientes (Murashige \& Skoog, 1962), e 6-benzilaminopurina (BAP) $\left(4 \mathrm{mg} \mathrm{L}^{-1}\right)$. Após cinco semanas, os ápices caulinares foram transferidos para meio com $2,5 \mathrm{mg} \mathrm{L}^{-1}$ de BAP e subcultivados por três vezes, a intervalos de 37 dias. Os meios foram suplementados com sacarose $\left(30 \mathrm{~g} \mathrm{~L}^{-1}\right)$ e Phytagel $\left(1,7 \mathrm{~g} \mathrm{~L}^{-1}\right)$, com $\mathrm{pH}$ ajustado para 5,8. Os explantes desenvolveram-se em sala de crescimento artificial com fotoperíodo de 16 horas, provido por lâmpadas fluorescentes do tipo luz do dia especial $\left(40 \mu \mathrm{mol} \mathrm{m} \mathrm{m}^{-2} \mathrm{~s}^{-1}\right)$, e temperatura de $25 \pm 2^{\circ} \mathrm{C}$.

Após os três subcultivos, os ápices caulinares foram submetidos a tratamentos com os antimitóticos. Para isso, as brotações tiveram o pseudocaule cortado a 5-8 mm acima da inserção com o rizoma, e algumas bainhas foliares foram removidas para facilitar a atuação do antimitótico nas células 
meristemáticas. Os tratamentos consistiram de concentrações de colchicina Sigma $(0,1,25,2,5,3,75$ e $5 \mathrm{mmol} \mathrm{L}^{-1}$ ) (Sigma-Aldrich Co., St. Louis, MO, EUA) e orizalina $\left(0,15,22,5\right.$ e $\left.30 \mu \mathrm{mol} \mathrm{L}^{-1}\right)$ Supelco, (Sigma-Aldrich Co., St. Louis, MO, EUA), com tempo de exposição de 24 e 48 horas para colchicina, e de 3 e 7 dias para orizalina, em esquema fatorial $5 \times 2$ e $4 \times 2$, respectivamente.

Após a aplicação dos tratamentos, os explantes (dez por frasco) foram mantidos em $40 \mathrm{~mL}$ de água destilada e autoclavada por 24 horas, a $120 \mathrm{rpm}$. Em seguida, os explantes foram transferidos para seis frascos (cinco explantes por frasco) contendo $40 \mathrm{~mL}$ de meio fresco semissólido - fase denominada de primeiro subcultivo pós-tratamento. Em todas as etapas da indução de poliploidização, o meio utilizado foi o MS suplementado com BAP $\left(2,5 \mathrm{mg} \mathrm{L}^{-1}\right)$ a pH 5,8. O meio líquido foi utilizado apenas na fase de aplicação dos tratamentos, tendo-se utilizado meio solidificado com Phytagel $\left(1,7 \mathrm{~g} \mathrm{~L}^{-1}\right)$ nas demais fases.

Trinta dias após o primeiro subcultivo, foram avaliados os seguintes parâmetros: percentual de sobrevivência de explante, número de brotações em cada explante inicial e número total de brotos. Após as avaliações, os explantes sobreviventes (brotações axilares e gemas existentes) foram subcultivados por mais duas vezes em meio fresco (MS com 2,5 $\mathrm{mg} \mathrm{L}^{-1}$ de BAP), em intervalos de 35 a 40 dias. As brotações produzidas desenvolveram-se em sala de crescimento artificial (fotoperíodo de 16 horas, $40 \mu \mathrm{mol} \mathrm{m} \mathrm{m}^{-2} \mathrm{~s}^{-1} \mathrm{e}$ $25 \pm 2^{\circ} \mathrm{C}$ ). Em seguida, as brotações foram alongadas e enraizadas em meio MS desprovido de BAP, sob luz natural, em estufa tipo Pad \& Fan, e as plantas obtidas foram aclimatizadas.

Utilizou-se o delineamento inteiramente casualizado, com seis repetições, representadas por um frasco com cinco explantes cada um, o que totalizou 30 explantes por tratamento. Os dados foram submetidos à análise de variância e ajustados às equações de regressão, quando necessário. Dados referentes à percentagem de sobrevivência e ao número de brotos foram transformados para arc sen $(\mathrm{x} / 100)^{0,5}$ e $(\mathrm{x}+1)^{0,5}$, respectivamente.

\section{Resultados e Discussão}

As respostas morfogenéticas e fisiológicas dos ápices caulinares submetidos à poliploidização variaram com o antimitótico, a concentração utilizada e o tempo de aplicação do tratamento. Diferenças também foram observadas entre os genótipos.

Quanto à aplicação in vitro de colchicina, houve interação significativa entre os fatores avaliados para a variável sobrevivência dos ápices caulinares (Figura 1), além de bom ajuste das equações de regressão para as características avaliadas, à exceção da variável número de brotos, no diploide Malbut.

De modo geral, houve tendência de redução na sobrevivência com o aumento da concentração e do tempo de exposição à colchicina, com maior intensidade a partir de 1,25 $\mathrm{mmol} \mathrm{L}^{-1}$, em 48 horas (Figuras 1 e 2). Quanto aos genótipos, o Malbut foi o menos sensível à colchicina (Figura 2). É importante destacar que, durante a primeira semana do primeiro subcultivo após a aplicação de colchicina, a maioria dos explantes permanecia com coloração verde, o que impossibilitou a diferenciação dos ápices caulinares vivos e mortos. Contudo, decorridas duas semanas, os ápices caulinares tratados apresentavam extremidades oxidadas (coloração escura), que evoluíram para necrose e morte do explante.

Esses resultados estão de acordo com os obtidos em outros trabalhos (Van Duren et al., 1996; Ganga \& Chezhiyan, 2002), nos quais o tratamento com colchicina, em concentrações de 2,5 a $10 \mathrm{mmol} \mathrm{L}^{-1}$, por 12, 24 e 36 horas, promoveu redução da sobrevivência dos explantes, em diploides de bananeira AA e AB. Entretanto, a amplitude de concentrações e o tempo de exposição utilizados foram superiores aos do presente trabalho. A maioria dos estudos realizados com Musáceas, exceto o conduzido por Bakry et al. (2007), utiliza concentrações maiores, múltiplas de 2,5 mmol L-1. De acordo com Hamill et al. (1992), muitos dos diploides de bananeira não são afetados pela aplicação do antimitótico, pois, logo no primeiro subcultivo pós-tratamento, os explantes tratados apresentam crescimento mais rápido e caracteres morfológicos típicos de plantas diploides in vitro.

$\mathrm{O}$ aumento da mortalidade e os demais efeitos fitotóxicos nos explantes, em consequência das concentrações e do tempo de exposição à colchicina, também foram observados em outras espécies, como Platanus acerifolia (Liu et al., 2007), Citrus sinensis Osbeck e Fortunella crassifolia (Zeng et al., 2006), e Lagerstroemia indica (Zhang et al. (2010). Grzebelus \& Adamus (2004), ao induzir poliploidização em 
embriões ginogênicos de Allium cepa, relataram que a colchicina provocou redução significativa na taxa de sobrevivência dos explantes, ao contrário do observado para o fator tempo de exposição, que não teve efeito significativo sobre a taxa de regeneração dos embriões.

Com relação à variável número médio de brotos, observou-se interação significativa entre os fatores somente no genótipo Malbut (Figura 1). Nenhum modelo polinomial (até o terceiro grau) foi ajustado à resposta do genótipo TDM aos tratamentos. Suas médias variaram de 0,63 brotos $\left(0 \mathrm{mmol} \mathrm{L}^{-1}\right)$ a 1,67 brotos $\left(5 \mathrm{mmol} \mathrm{L}^{-1}\right)$, com 24 horas de exposição à colchicina, e de 1,27 brotos $\left(0 \mathrm{mmol} \mathrm{L}^{-1}\right)$ a 0,08 brotos $\left(5 \mathrm{mmol} \mathrm{L}^{-1}\right)$, no tratamento de 48 horas. No genótipo NBA-14, não houve efeito significativo do fator concentração, apenas do tempo de exposição, em que o maior e o menor número de brotos foram observados com 24 horas (1,46 brotos) e 48 horas $(0,50$ brotos $)$, respectivamente $(\mathrm{p}<0,01)$. No diploide
Malbut, houve tendência de incremento do número médio de brotos com o aumento da concentração de colchicina, com 24 horas de exposição, mas tendência de redução, com 48 horas, principalmente em concentrações maiores que $2,5 \mathrm{mmol} \mathrm{L}^{-1}$ de colchicina (Figuras 1 e 2).

A redução da emissão de novas brotações, em resposta ao tratamento com colchicina, assim como as diferenças observadas entre os genótipos diploides, corroboram os resultados obtidos em outros trabalhos (Van Duren et al., 1996; Ganga \& Chezhiyan, 2002).

Embora tenha ocorrido morte da maioria dos ápices caulinares, verificou-se que, com o tempo de cultivo in vitro, grande parte dos explantes mostrou indução de gemas axilares, provavelmente como consequência da quebra de dominância apical após a morte do ápice caulinar tratado. Em bananeira, a indução de novas brotações em resposta à quebra da dominância apical é uma característica intrínseca ao
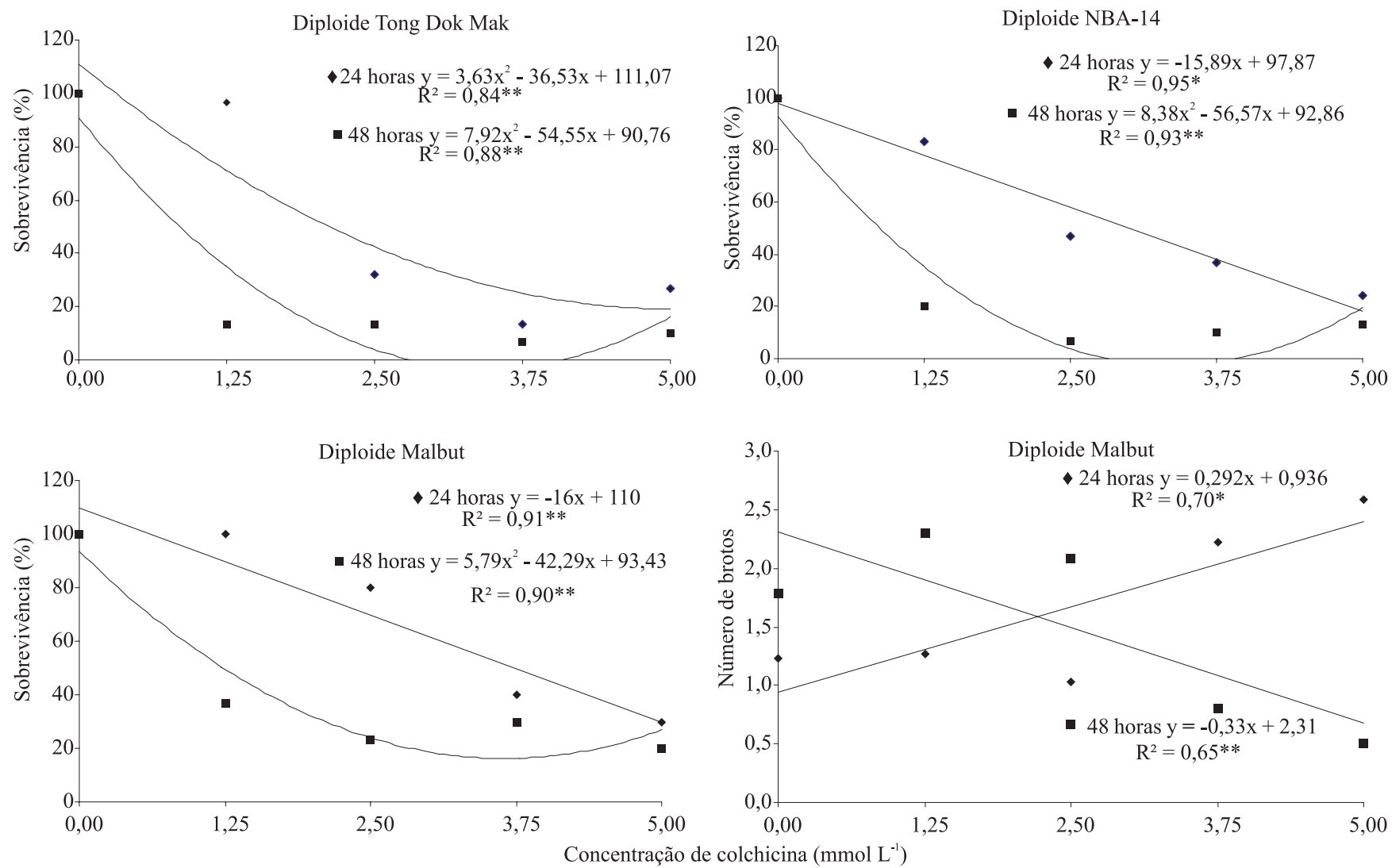

Figura 1. Sobrevivência e número de brotações de explantes de genótipos diplóides de bananeira, em função das concentrações de colchicina e do tempo de exposição avaliados. * e**Significativo a 5 e $1 \%$ de probabilidade, respectivamente. 

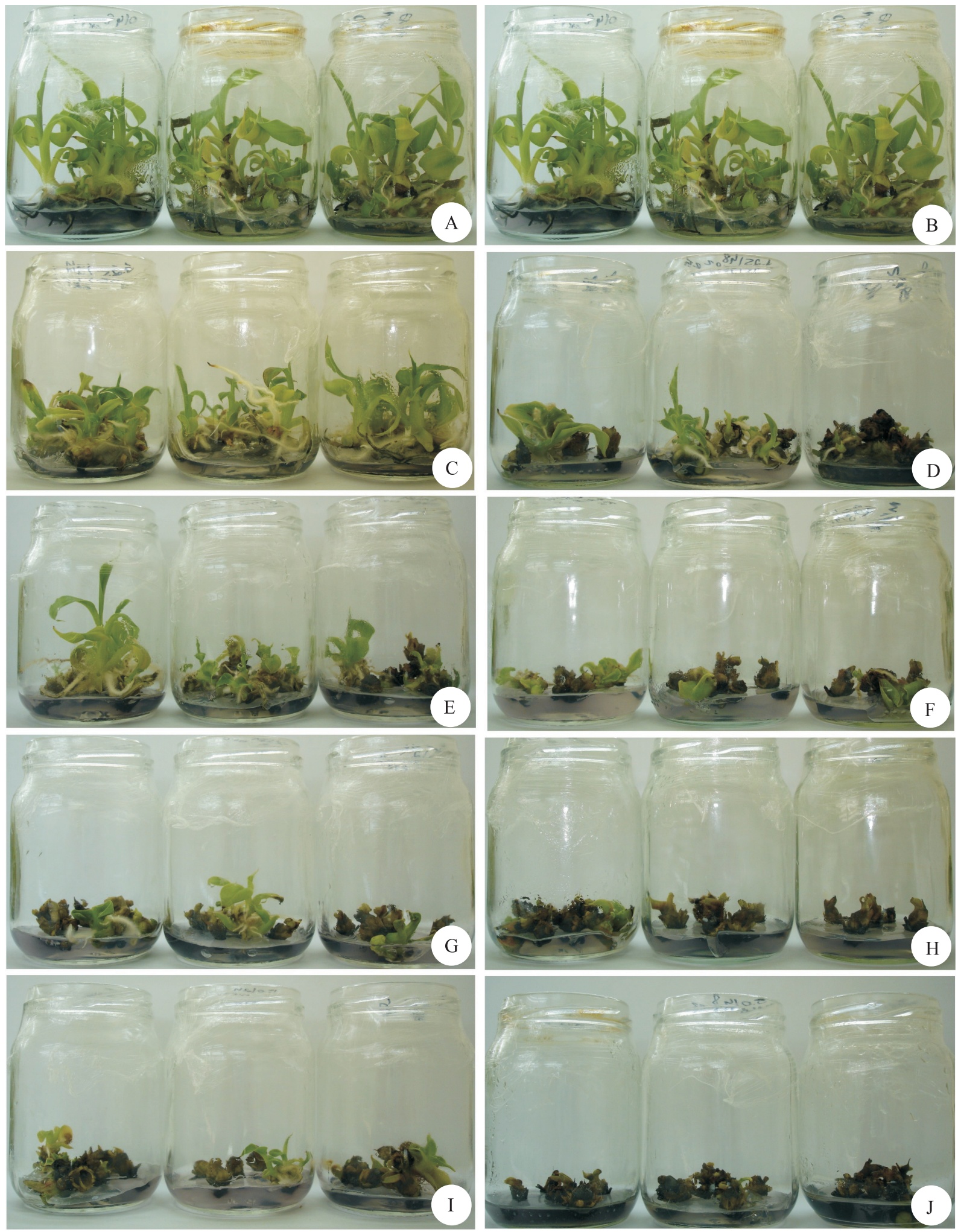

Figura 2. Efeitos morfofisiológicos in vitro da indução de autotetraploides no genótipo Malbut, de bananeira pelo uso de colchicina, aos 30 dias após o primeiro subcultivo. Concentrações de colchicina: $0 \mathrm{mmol} \mathrm{L}^{-1}$ por 24 horas (A) e 48 horas (B); $1,25 \mathrm{mmol} \mathrm{L}^{-1}$ por 24 horas (C) e 48 horas (D); $2,5 \mathrm{mmol} \mathrm{L}^{-1}$ por 24 horas (E) e 48 horas (F); $3,75 \mathrm{mmol} \mathrm{L}^{-1}$ por 24 horas (G) e 48 horas $(\mathrm{H}) ; 5,0 \mathrm{mmol} \mathrm{L}^{-1}$ por 24 horas (I) e 48 horas (J). 
cultivo in vitro da espécie e está relacionada a danos físicos ou a efeitos de reguladores de crescimento na região meristemática do ápice caulinar (Scherwinski-Pereira et al., 2009).

A indução de novas brotações é intensificada após os sucessivos subcultivos, possivelmente pela redução do efeito residual do antimitótico associada à retomada da capacidade de multiplicação dos explantes tratados. Portanto, os explantes avaliados como mortos ainda podem produzir novas brotações com o tempo de cultivo, dependendo do tempo decorrido após a aplicação do antimitótico.

O uso de colchicina também resultou na formação de massas de células não diferenciadas, como calos compactos na base dos explantes, na maior oxidação dos explantes, na redução da emissão de raízes e de folhas, e na hiperhidricidade, principalmente com o aumento da concentração e do tempo de exposição à colchicina (Figura 2). É importante ressaltar que a maioria dos explantes tratados teve crescimento mais lento e, em alguns casos, apresentaram desenvolvimento de folhas com aspecto de poliploide, ou seja, mais espessas e com maior área. As características poliploides observadas no presente trabalho foram utilizadas na pré-seleção in vitro, para reduzir o tempo e o trabalho do melhorista na identificação dos prováveis poliploides e na confirmação dos autotetraploides. Esses resultados estão de acordo com os obtidos por Hamill et al. (1992), que, ao avaliar plantas poliploides, sob condições in vitro, observaram maior área foliar, pseudocaule mais espesso e coloração verde mais intensa.

Quanto à aplicação in vitro de orizalina, foi observada interação significativa entre os fatores avaliados, à exceção do número médio de brotos no diploide NBA-14. Para os genótipos TDM e NBA-14, observou-se tendência de redução na sobrevivência com o aumento da concentração de orizalina, independentemente do tempo de exposição (Figura 3). No entanto, a redução na sobrevivência foi menor em comparação à colchicina, o que confirma os resultados de Khosravi et al. (2008). De acordo com os autores, a indução de poliploidização mediante a aplicação de orizalina apresenta vantagens, como baixa fitotoxidez in vitro, maior afinidade com a proteína do fuso mitótico (tubulina) e concentrações mil vezes menores, com eficiência similar ou superior à da colchicina.
Com relação ao número médio de brotos, o genótipo TDM apresentou comportamento quadrático quando os ápices caulinares foram tratados por três dias, mas resposta linear, aos sete dias, com tendência de aumento do número de brotos com o incremento na concentração de orizalina (Figura 3). No genótipo NBA-14, apenas o fator concentração de orizalina teve efeito significativo, com comportamento quadrático.

O aumento da proliferação de brotações em resposta à aplicação de orizalina (Figura 3) pode ser atribuído ao fato de alguns herbicidas do grupo das dinitroanilinas, como a orizalina, estimularem o crescimento de plantas, quando usados em baixas concentrações (Van Duren et al., 1996; Ganga \& Chezhiyan, 2002).

No presente trabalho, a indução de poliploidia com orizalina promoveu diferentes respostas morfogenéticas, como a ocorrência de multibrotações na maioria dos ápices caulinares tratados (Figura 4). Essa resposta dificultou a imediata individualização dos brotos após o primeiro subcultivo. A estratégia utilizada, nos dois primeiros subcultivos, foi retirar as partes oxidadas e subdividir os explantes em pequenos fragmentos ou em grupos de pequenas brotações ("clusters"), até uma melhor diferenciação de gemas em brotos, que só ocorreu no segundo e terceiro subcultivos. Portanto, é essencial conhecer os efeitos in vitro da aplicação de antimitóticos, para ter subsídios para a implementação de estratégias de cultivo e para a tomada de decisões nas etapas de planejamento e condução de experimentos semelhantes.

A aplicação de altas concentrações de orizalina causou redução no crescimento in vitro, diminuição no número de folhas expandidas (Figura 4) e menor nível de oxidação fenólica, o que possivelmente favoreceu a indução de maior número de brotos, em comparação ao tratamento com colchicina.

Em trabalho semelhante, Van Duren et al. (1996), ao avaliar os antimitóticos colchicina e orizalina na indução de poliploidia em bananeira, constataram que explantes tratados com colchicina apresentaram de 0 a $73 \%$ de sobrevivência, e que esse percentual variou de 0 a $80 \%$ com orizalina. Segundo os autores, a aplicação dos antimitóticos causou, em geral, baixa taxa de regeneração e afetou significativamente a massa dos brotos regenerados, em comparação aos ápices caulinares não tratados. Além disso, as plantas tratadas com orizalina tiveram tendência de 
produzir mais brotos; porém, a massa e a dimensão dos novos brotos foram sempre menores, em comparação às das plantas controle. Esses resultados discordam dos de Ganga \& Chezhiyan (2002), que verificaram que a aplicação de orizalina a baixas concentrações $\left(10\right.$ e $\left.20 \mu \mathrm{mol} \mathrm{L}^{-1}\right)$ resultou em maior taxa de multiplicação por cultura.

Ao contrário da colchicina, a indução de poliplopidização pelo uso de orizalina promoveu reduzida oxidação por fenóis, menor fitotoxidez e morte dos explantes, e, na maioria dos tratamentos, indução de novas brotações. Embora a indução de poliploides com colchicina tenha causado maior fitotoxicidade nos ápices caulinares, a capacidade morfogenética dos explantes foi retomada à medida que se realizaram os subcultivos.

As plantas produzidas após a aclimatização apresentaram ampla variação de tamanho e, em alguns casos, houve morte de plantas após a transferência ex vitro. Essas perdas podem ter sido decorrentes do tamanho reduzido de algumas brotações e da baixa quantidade de reservas existentes (acúmulo de matéria seca da parte aérea e do rizoma). No entanto, ainda houve alta percentagem de sobrevivência, acima de 90\%. É provável que o sucesso na aclimatização das plantas seja resultado da utilização da luz natural na fase de enraizamento e alongamento in vitro. De acordo com Costa et al. (2009), o uso da luz natural nessas etapas promove rustificação e melhoria das plantas de bananeira produzidas, com maior espessamento dos parênquimas clorofilianos, paliçádicos e esponjosos, além de redução da perda de água foliar decorrente da melhoria da funcionalidade dos estômatos.
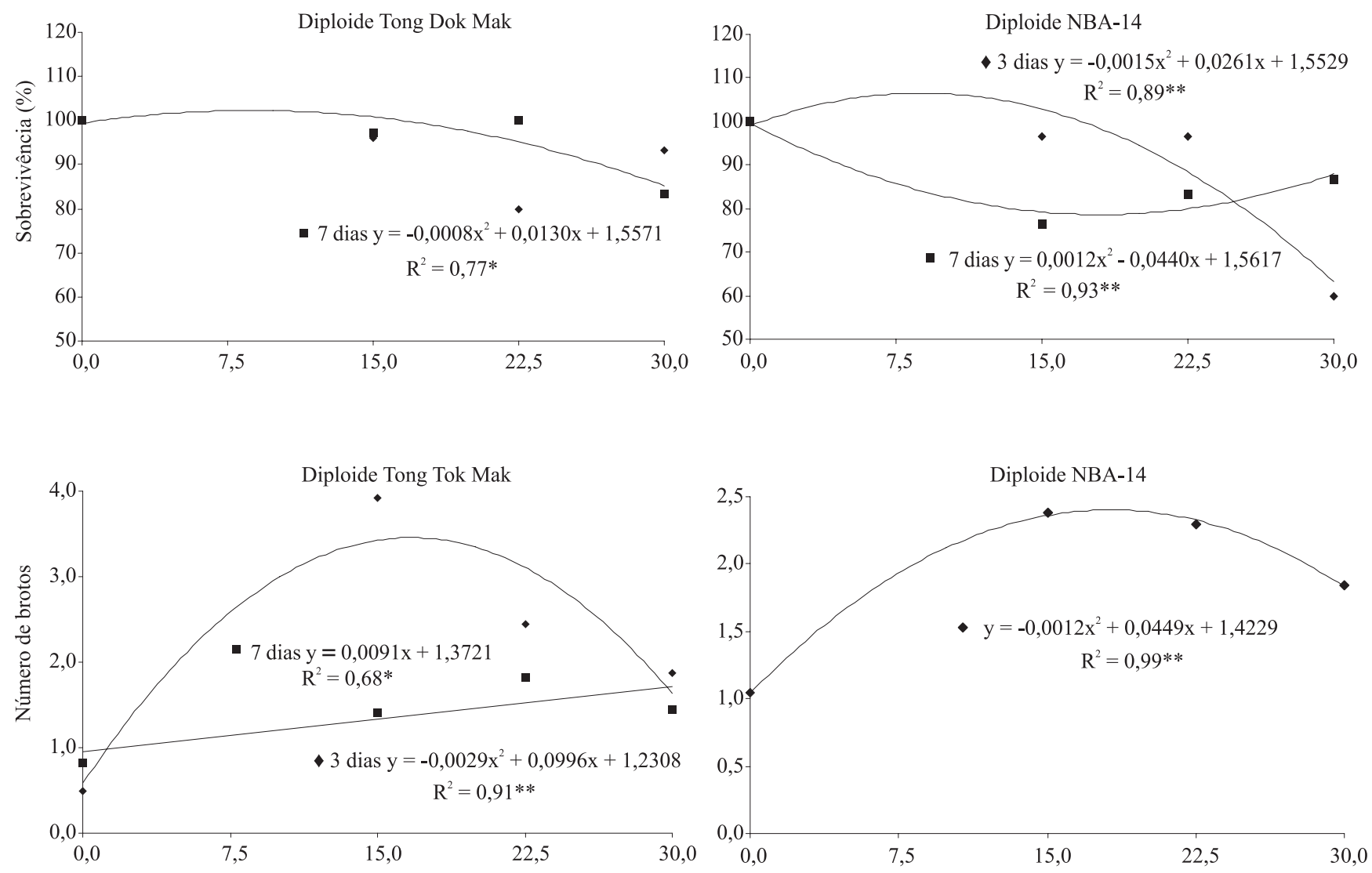

Concentração de orizalina $\left(\mu \mathrm{mol} \mathrm{L}{ }^{-1}\right)$

Figura 3. Sobrevivência e número médio de brotações de explantes de genótipos diploides de bananeira (TDM e NBA-14), em função das concentrações de orizalina e do tempo de exposição ( 3 e 7 dias). * e **Significativo a 5 e $1 \%$ de probabilidade, respectivamente. 

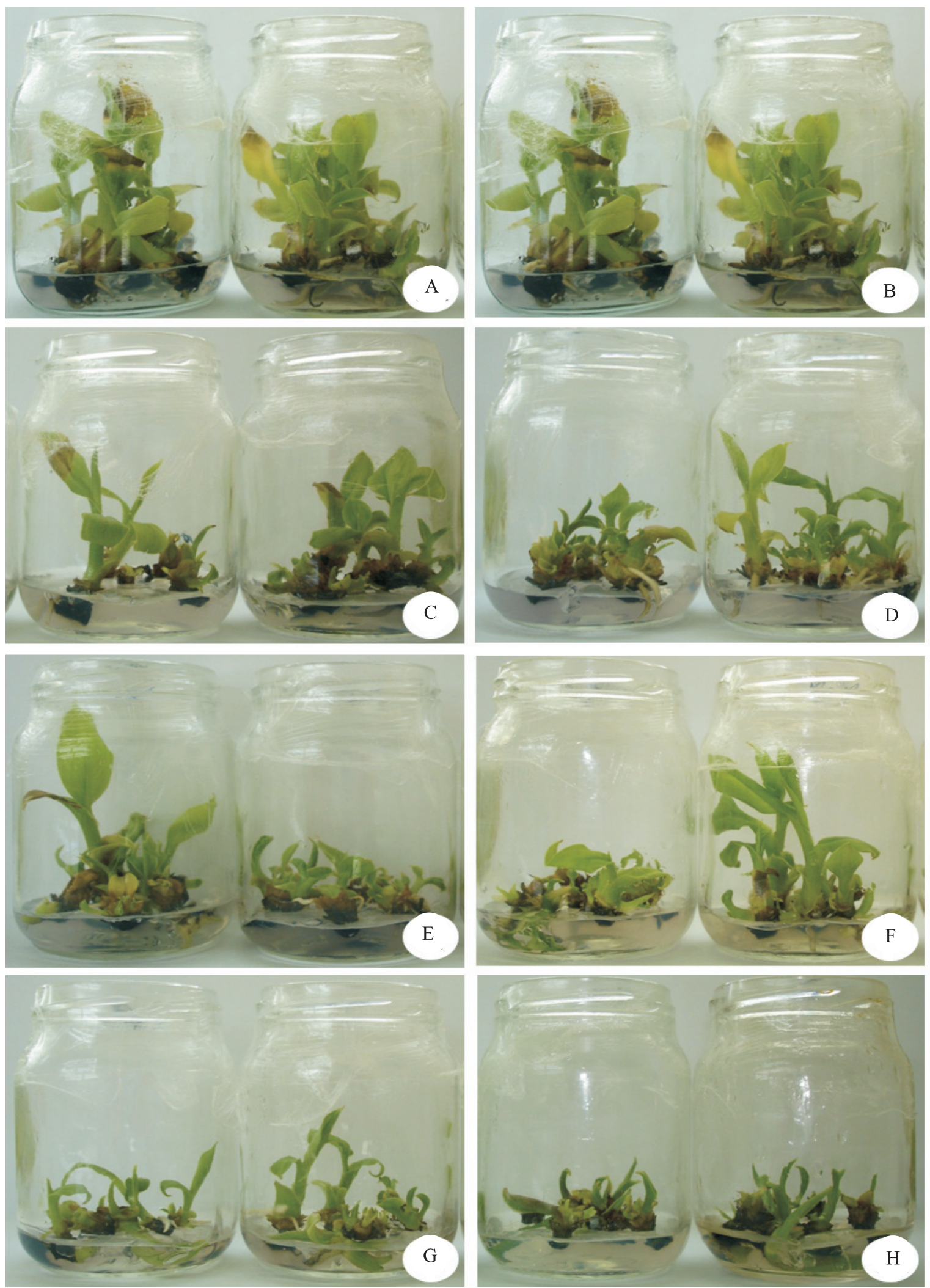

Figura 4. Efeitos morfofisiológicos in vitro da indução de autotetraploides no genótipo Tong Dok Mak, de bananeira, pelo uso de orizalina, aos 30 dias após o tratamento. Concentrações de orizalina: $0 \mu \mathrm{mol} \mathrm{L}^{-1}$ por 3 (A) e 7 dias (B); 15 $\mu \mathrm{mol} \mathrm{L} \mathrm{L}^{-1}$ por $3(\mathrm{C})$ e 7 dias (D); 22,5 $\mu \mathrm{mol} \mathrm{L}^{-1}$ por $3(\mathrm{E})$ e 7 dias (F); $30 \mu \mathrm{mol} \mathrm{L}^{-1}$ por $3(\mathrm{G})$ e 7 dias (H). 


\section{Conclusões}

1. A colchicina apresenta maior fitotoxidez que a orizalina; no entanto, promove maior variabilidade morfológica nas plantas regeneradas.

2. A indução de poliploidização com orizalina aumenta a indução de novos brotos axilares.

3. As concentrações de 1,25 e $3,75 \mathrm{mmol} \mathrm{L}^{-1}$ de colchicina e o uso de orizalina representam novas abordagens para o melhoramento da bananeira via indução de poliploides.

4. Os efeitos morfofisiológicos observados in vitro são importantes para definir estratégias de indução de poliploidia em bananeira.

\section{Agradecimentos}

Ao Conselho Nacional de Desenvolvimento Científico e Tecnológico, pelo apoio financeiro; e ao Campo Biotecnologia, por ceder a infraestrutura para enraizamento sob luz natural e aclimatização.

\section{Referências}

ASIF, M.J.; MAK, C.; YASMIN, O.R. Polyploid induction in a local wild banana (Musa acuminata ssp. malaccensis). Pakistan Journal of Biological Sciences, v.3, p.740-743, 2000.

BAKRY, F.; CARREEL, F.; JENNY, C.; HORRY, J.-P. Genetic improvement of banana. In: JAIN, S.M.; PRIYADARSHAN, P.M. (Ed.). Breeding plantation tree crops: tropical species. New York: Springer, 2009. p.3-46.

BAKRY, F.; REBERDIERE, N.P. de la; PICHOT, S.; JENNY, C. In liquid medium colchicine treatment induces non chimerical doubled-diploids in a wide range of mono- and interspecific diploid banana clones. Fruits, v.62, p.3-12, 2007.

COSTA, F.H. da S.; PASQUAL, M.; SCHERWINSKI-PEREIRA, J.E.S.; CASTRO, E.M. de. Anatomical and physiological modifications of micropropagated 'caipira' banana plants under natural light. Scientia Agricola, v.66, p.323-330, 2009.

GANGA, M.; CHEZHIYAN, N. Influence of the antimitotic agents colchicine and oryzalin on in vitro regeneration and chromosome doubling of diploid bananas (Musa spp.). Journal of Horticultural Science and Biotechnology, v.77, p.572-575, 2002.

GRZEBELUS, E.; ADAMUS, A. Effect of anti-mitotic agents on development and genome doubling of gynogenic onion (Allium cepa L.) embryos. Plant Science, v.167, p.569-574, 2004.

HAMILL, S.D.; SMITH, M.K.; DODD, W.A. In vitro induction of banana autotetraploids by colchicine treatment of micropropagated diploids. Australian Journal of Botany, v.40, p.887-896, 1992.

KHOSRAVI, P.; KERMANI, M.J.; NEMATZADEH, G.A.; BIHAMTA, M.R.; YOKOYA, K. Role of mitotic inhibitors and genotype on chromosome doubling of Rosa. Euphytica, v.160, p.267-275, 2008

LIU, G.F.; LI, Z.N.; BAO, M.Z. Colchicine-induced chromosome doubling in Platanus acerifolia and its effect on plant morphology. Euphytica, v.157, p.145-154, 2007.

MURASHIGE, T.; SKOOG, F. A revised medium for rapid growth and bioassays with tobacco tissue cultures. Physiologia Plantarum, v.15, p.473-497, 1962.

SCHERWINSKI-PEREIRA, J.E.; COSTA, F.H.S.; OLIVEIRA, J.P. Micropropagação de bananeira visando à produção massal de mudas de elevado padrão genético e fitossanitário. In: GONÇALVES, R.C.; OLIVEIRA, L.C. de (Ed.). Embrapa Acre: ciência e tecnologia para o desenvolvimento sustentável do Sudoeste da Amazônia. Rio Branco: Embrapa Acre, 2009. p.247-284.

SILVA, S. de O. e; ALVES, E.J.; LIMA, M.B.; SILVEIRA, J.R.S. Bananeira. In: BRUCKNER, C.H. (Ed.). Melhoramento de fruteiras tropicais. Viçosa: UFV, 2002. p.101-157.

SILVA, S. de O. e; SOUZA JÚNIOR, M.T.; ALVES, E.J.; SILVEIRA, J.R.S.; LIMA, M.B. Banana breeding program at Embrapa. Crop Breeding and Applied Biotechnology, v.1, p.399-436, 2001.

VAN DUREN, M.; MORPURGO, R.; DOLEZEL, J.; AFZA, R. Induction and verification of autotetraploids in diploid banana (Musa acuminate) by in vitro techniques. Euphytica, v.88, p.25-34, 1996.

ZENG, S.-H.; CHEN, C.-W.; HONG, L.; LIU, J.-H.; DENG, X. In vitro induction, regeneration and analysis of autotetraploids derived from protoplasts and callus treated with colchicine in Citris. Plant Cell Tissue and Organ Culture, v.87, p.85-93, 2006.

ZHANG, Q.Y.; LUO, F.X.; LIU, L.; GUO, F. In vitro induction of tetraploids in crape myrtle (Lagerstroemia indica L.). Plant Cell Tissue and Organ Culture, v.101, p.41-47, 2010. 